\title{
Recorregut peripatètic de recerca geològica per la comarca del Vallès Oriental: des de la urbanització del Farell a Sant Sebastià de Montmajor i al Turó del Vent
}

Josep Maria Mata-Perelló

Joaquim Sanz Balagué

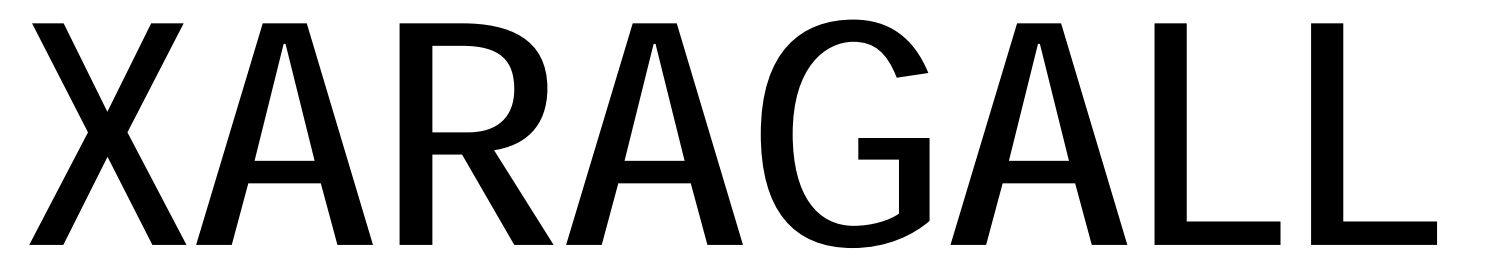

REVISTA DE CIÈNCIES DE LA CATALUNYA CENTRAL

\section{n. 12}

DESEMBRE 2014 


\title{
RECORREGUT PERIPATÈTIC DE RECERCA GEOLÒGICA PER LA COMARCA DEL VALLÈS ORIENTAL: DES DE LA URBANITZACIÓ DEL FARELL A SANT SEBASTIÀ DE MONTMAJOR I AL TURÓ DEL VENT
}

\author{
Josep Maria Mata-Perelló \\ Museu de geologia Valentí Masachs, Escola Politècnica Superior d'Enginyeria de Manresa \\ (EPSEM), Universitat Politècnica de Catalunya · BarcelonaTech (UPC), 08272 Manresa, Spain
}

\section{Joaquim Sanz Balagué}

Departament d'Enginyeria Minera i Recursos Naturals (EMRN), Escola Politècnica Superior d'Enginyeria de Manresa (EPSEM), Universitat Politècnica de Catalunya . BarcelonaTech (UPC), 08272 Manresa, Spain

Paraules clau: Serralada Prelitoral, Depressió Geològica de l'Ebre, Patrimoni miner

\section{Resum}

Itinerari realitzat l'1 de febrer de 2014. En aquesta ocasió, el recorregut de l'itinerari discorrerà, en la seva quasi totalitat pel Sistema Mediterrani, i més concretament per la Serralada Prelitoral Catalana (la seva unitat més externa). Així doncs, la quasi totalitat del recorregut pel Farell, es realitzarà per aquesta unitat geològica

Tot i així, en els trams entremitjos s'entrarà a la Depressió Geològica de l'Ebre, pels voltants de Sant Sebastià de Montmajor.

Per d'altra banda, i com ja s'entreveu al títol, el recorregut de l'itinerari discorrerà sols per la comarca del Vallès Oriental. 


\section{Objectius fonamentals}

Els objectius fonamentals que es pretenen aconseguir en aquest itinerari, es poden concretar en els següents aspectes generals:

1. Observació i descripció dels materials mesozoics (del Triàsic, exclusivament) i paleozoics (fonamentalment de l'Ordovicià) de la Serralada Prelitoral Catalana, que es troben al llarg de bona part del recorregut de l'itinerari.

2. Observació dels materials cenozoics (del Paleocè i de l'Eocè), que es troben a les parts intermitges del recorregut de l'itinerari, i que pertanyen a la Depressió Geològica de I’Ebre.

3. Observació de les estructures locals d'aquests materials, al llarg del recorregut de l'itinerari. Així com de les relacions entre les diferents unitats geològiques on es troben situades.

4. Observació dels diferents elements del Patrimoni Geològic (i si s'escau del Patrimoni Miner), que es vagin trobant al llarg del recorregut de l'itinerari.

\section{Antecedents}

Pel que fa al recorregut del present itinerari, cal dir que no hem sabut trobar cap antecedent bibliogràfic publicat, en relació al mateix. Nosaltres mateixos, és la primera vegada que realitzem un recorregut geològic per aquests indrets. Així, aquest recorregut podria ésser una primícia.

Pel que fa a la descripció de les mineralitzacions, farem esment del treball del mateix autor del present itinerari, Mata-Perelló (1991), relatiu al conjunt de les mineralitzacions catalanes.

I, finalment, pel que fa a l'estructura geològica de la zona per la qual discorre l'itinerari, farem esment dels treballs de: Guimerà et altri (1982) i de Riba et altri (1976); així com del full 392 de I'IGME (1976).

Tots aquests treballs referenciats, i d'altres, figuren esmentats per ordre alfabètic a l'apartat dedicat a la BIBLIOGRAFIA.

\section{Recorregut de l'itinerari}

La totalitat del recorregut de l'itinerari es situarà dintre de la comarca del Vallès Oriental. És més, la pràctica totalitat del mateix es realitzarà pel terme municipal de Caldes de Montbui. Tot i això, molt parcialment, també s'entrarà al llindar amb el terme de Sentmenat, situat dintre de la comarca del Vallès Occidental.

Així, s'iniciarà a la Urbanització del Farell, situada a la carretera BV - 1243 (procedent de Caldes de Montbui). Des d'aquí, s'anirà cap el proper poblet de Sant Sebastià de Montmajor, seguint la carretera.

A partir d'aquest indret es pujarà per un caminet cap el Turó de Sant Sebastià, des d'on s'anirà cap al Turó dels Tres Pins (per on s'entrarà breument al terme de Sentmenat). Després s'anirà 
cap al Turó del Vent, des d'on es tornarà cap a la Urbanització del Farell, finalitzant el recorregut de l'itinerari.

\section{Advertiments previs}

Com en altres recorreguts de RECERCA GEOLÒGICA I MINERALÒGICA ..., si es disposa del temps suficient, poden efectuar-se passant per totes les parades i filloles. En cas contrari, recomanem prescindir de les anomenades PARADES - CONDICIONALS.

En aquest itinerari, la totalitat del mateix es realitzarà totalment a peu, per camins de muntanya i també per carretera; encara que en aquest cas serà mínim.

Com en tots els altres itineraris, recomanem tenir una cura molt especial de respecte a la natura, al llarg de tot el recorregut del mateix.

\section{Descripció de l'itinerari}

Com de costum, estructurarem el recorregut de l'itinerari en una sèrie de PARADES, que tot seguit anirem veient. En cadascuna d'aquestes aturades farem un breu comentari. En cada cas indicarem, entre parèntesi, el full topogràfic on es troba l'aturada, i la designarem amb el nom d'algun topònim proper, fent esment també del terme municipal on es troba situada.

Finalment, cal dir que el recorregut de l'itinerari s'inclourà totalment dintre del full $n^{\circ} 392$ (o de Sabadell), del "Mapa Topográfico Nacional", realitzat a l'escala 1:50.000 per I'Instituto Geográfico y Catastral de España. També s'utilitzarà el mapa comarcal del Vallès Oriental, a escala 1:50.000, editat per I'Institut Cartogràfic de Catalunya.

Així, les diferents aturades que anirem trobant al llarg del recorregut, d'acord amb el seu ordre, seran les següents.

\subsection{Parada 1. CARRETERA BV - 1243, IMMEDIACIONS DEL Km 10`5, (Sant Sebastià de Montmajor, terme municipal de Caldes de Montbui, comarca del Vallès Oriental). (Full 392).}

El recorregut de l'itinerari el començarem a l'entrada de la Urbanització del Farell, situada a la carretera BV - 1243. Aquesta carretera parteix de Caldes de Montbui. Nosaltres I'agafarem ara, per tal d'anar a peu cap al poblet de Sant Sebastià de Montmajor. En principi anirem baixant, per tal de planejar després. En arribar a les immediacions del Km $10^{\prime} 5$ farem una primera aturada, després de recórrer entre 1' 5 i $2 \mathrm{Km}$ des del començament.

En aquest recorregut hem anat trobant afloraments dels materials triàsics que formen part de la Serralada Prelitoral Catalana. És a dir: ehem estat situats i encara ho estem dintre del Sistema Mediterrani. 
Tot i això, prop nostre hi ha afloraments dels materials rogencs de la base del Paleocè, els quals formen part de la Depressió Geològica de l'Ebre. També, més enllà, cap el Nord d'on ara som, es fan palesos els relleus dels Cingles de Gallifa, integrants d'aquesta depressió, però amb materials marins.

En aquest indret hi ha un aflorament dels materials carbonatats del Triàsic Mig, concretament del Muschelkalk Superior. Així, ara estem veient afloraments de les calcàries i de les dolomies, d'aquesta unitat geològica. Aquests materials es presenten aquí amb un suau cabussament. Aquests materials també es fan clarament palesos per sobre d'on ens trobem, entre els relleus septentrionals del Farell. (fotografia 1).

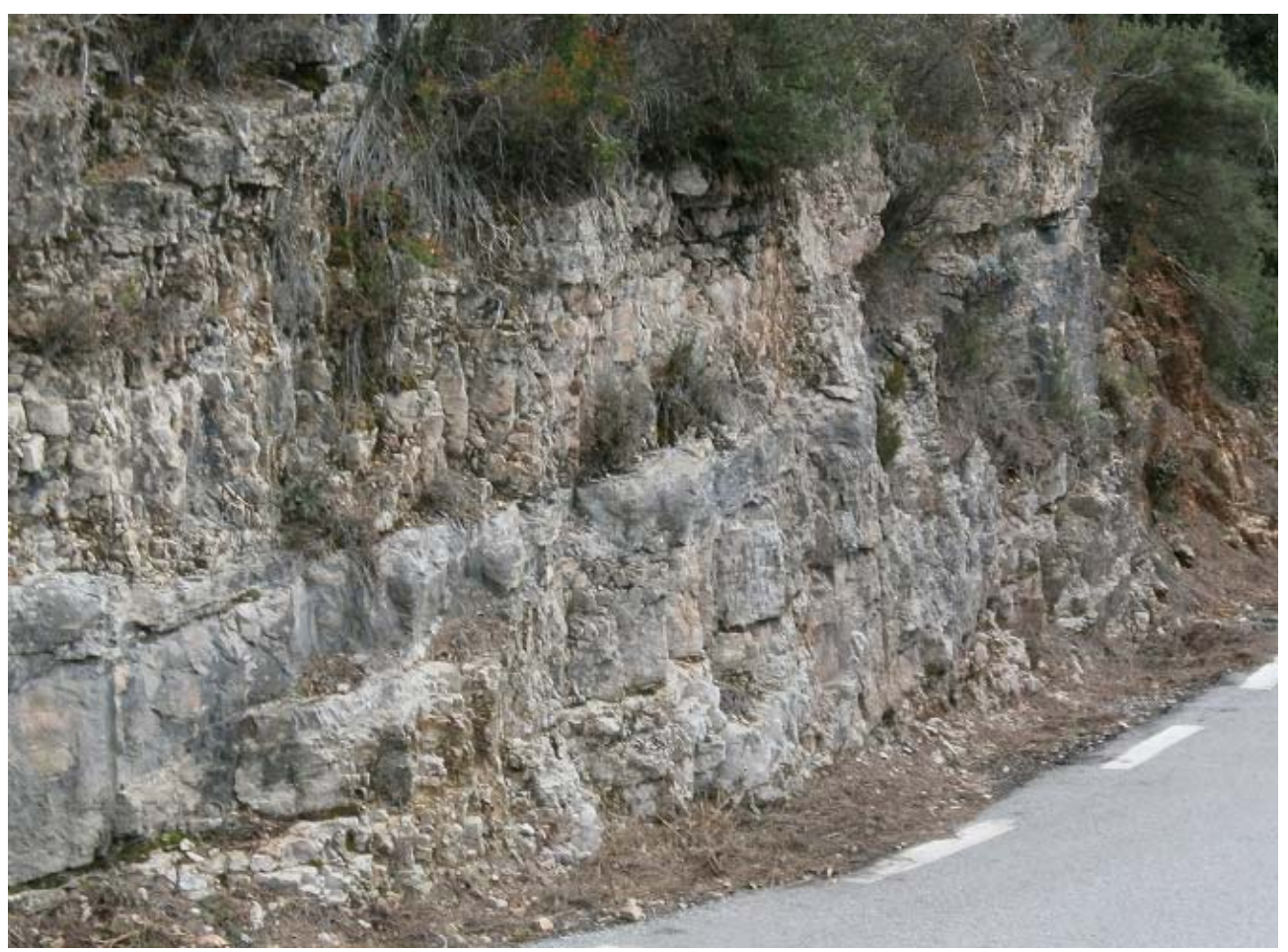

Fotografia 1. Afloraments dels materials carbonatats del Muschelkalk Superior

Carretera de Caldes de Montbui a Sant Sebastià de Montmajor, prop del Km 10’5

\subsection{Parada 2. EL "RELLOTGE", (Sant Sebastià de Montmajor, terme municipal de Caldes de Montbui, comarca del Vallès Oriental). (Full 392).}

Després de realitzar la parada anterior, caldrà continuar per la carretera local BV-1243, fent un curt recorregut d'uns 1'5 Km. Així, arribarem al poble de Sant Sebastià de Montmajor. En arribar-hi, caldrà envoltar-lo per dalt, amb la finalitat d'anar cap a l'indret del Rellotge, per on farem una nova aturada, a poc més de $2 \mathrm{Km}$ després de realitzar la parada anterior.

En aquest recorregut, hem trobat inicialment els materials esmentats a l'aturada anterior; és a dir: els nivells carbonatats del Muschelkalk Superior (dintre del Triàsic Mig). Aquests materials formen part de la Serralada Prelitoral Catalana (integrant del Sistema Mediterrani), com hem vist a l'aturada anterior.

Tot i així, en arribar a les immediacions del poble, haurem començat a trobar uns nivells de calcolutites i de gresos de tonalitats rogenques. Aquests materials pertanyen al Paleocè de la 
Depressió Geològica de l'Ebre. Aparentment, aquests materials es troben en posició concordant amb els terrenys triàsics que hem trobat anteriorment, especialment a l'aturada anterior.

Tot $\mathrm{i}$ així, més amunt d'on ara som, aquests materials del Cenozoic Inferior, es troben encavalcats pels terrenys mesozoics triàsics, del Muschelkalk Superior de la Serra del Farell. Tot i així, en aquest indret afloren els materials cenozoics, esmentats anteriorment, pels voltant del "rellotge". (fotografia 2)

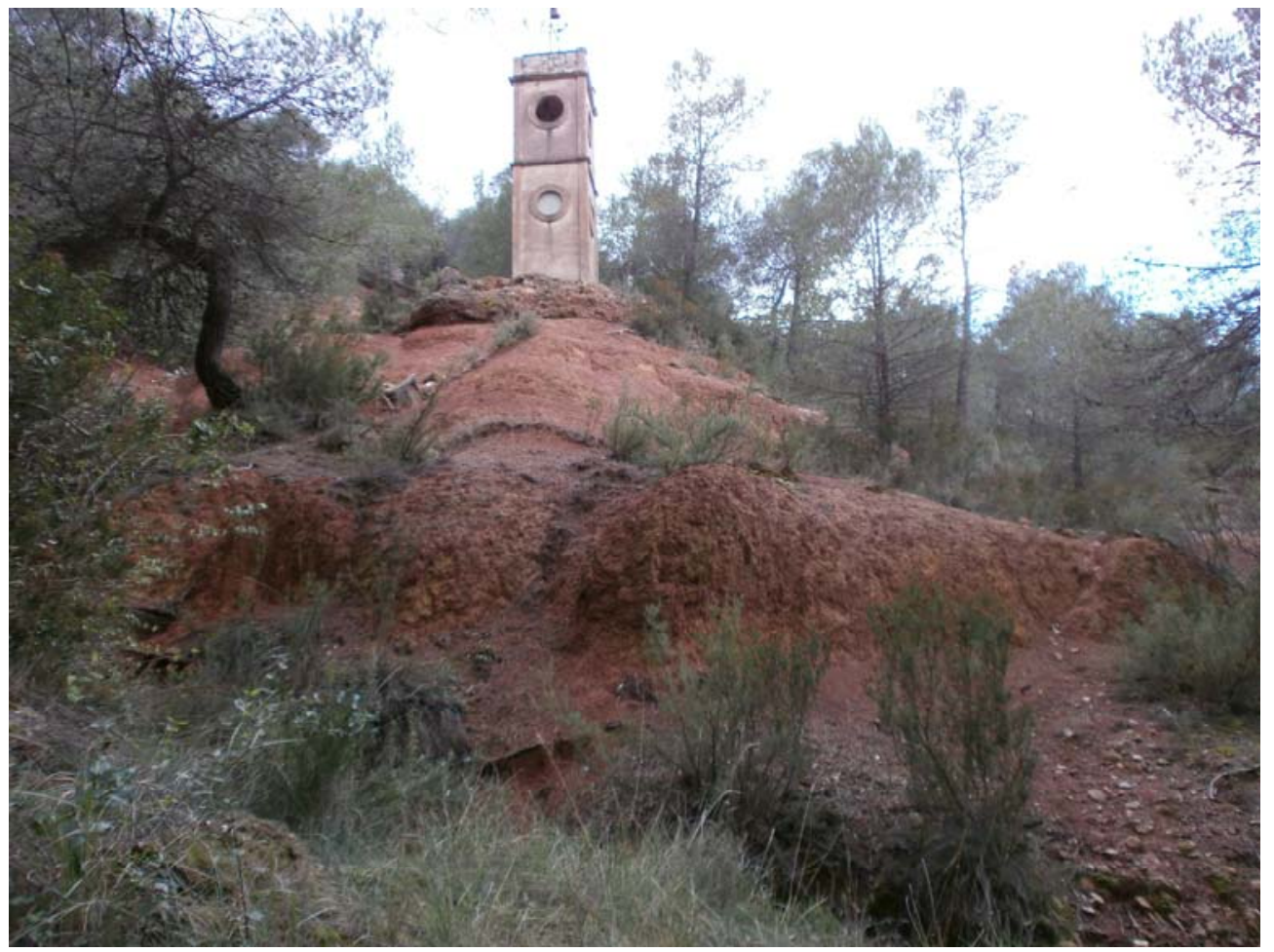

Fotografia 2. Afloraments dels materials continentals del Cenozoic Inferior, del Paleocè.

El rellotge, de Sant Sebastià de Montmajor

\subsection{Parada 3. TURÓ DE SANT SEBASTIÀ, (Sant Sebastià de Montmajor, terme municipal de Caldes de Montbui, comarca del Vallès Oriental). (Full 392).}

Després dec realitzar l'aturada anterior, cal efectuar un recorregut a peu, d'uns 1'5 Km, amb la finalitat d'arribar fins al Turó de Sant Sebastià. En aquest indret efectuarem una nova aturada.

En aquest recorregut, haurem continuat trobant afloraments dels materials rogencs del Cenozoic Inferior. Aquests materials, del Paleocè, es troben constituïts per nivells de gresos i de calcolutites rogenques.

Precisament, aquests són els materials que apareixen a l'indret de la present aturada; i també per tots els voltants del Turó de Sant Sebastià, per on ens trobem ara situats en aquest indret. 


\subsection{Parada 4. TURÓ DELS TRES PINS, (terme municipal de Sentmenat, comarca del Vallès Occidental). (Full 392).}

Després de realitzar l'aturada anterior, cal continuar caminant, per tal d'arribar fins al Turó dels Tres Pins. En arribar-hi, farem una nova aturada, a poc més de $2 \mathrm{Km}$ de la parada anterior. En aquest recorregut, hem passat breument del terme de Caldes de Montbui (del Vallès Oriental) al terme de Sentmenat (del Vallès Occidental), per on ens trobem ara situats.

En aquest recorregut, hem continuat trobant inicialment, els materials esmentats a la parada anterior; és a dir: els nivells de gresos i de calcolutites rogenques del Cenozoic Inferior. Així, aquests són també els materials que apareixen per les proximitats de l'indret de la present aturada.

Tot i això, en aquest indret del Turó de Tres Pins, apareix l'aflorament d'uns materials esquistosos, els quals pertanyen a l'Ordovicià. Aquests materials es troben encavalcant ala anteriors, als cenozoics que hem estat trobant en tot el camí. Malgrat això, l'encavalcament és molt petit, de reduïda extensió. En realitat es tracta de les restes ailllades d'un encavalcament molt més gran (que possiblement anava des de Matadepera a Sant Feliu de Codines), cobrint materials mesozoics i cenozoics. Després s'hauria erosionat, donant lloc a finestres tectòniques (on es mostra el que havia quedat encavalcat) i klipps tectònics o illes tectòniques (amb restes aïllats de l'encavalcament), com és el cas del Turó dels Tres Pins, entre altres indrets propers.

\subsection{Parada 5. TURÓ DEL VENT, (Sant Sebastià de Montmajor, terme municipal de Caldes de Montbui, comarca del Vallès Oriental). (Full 392).}

Després de realitzar l'aturada anterior, cal anar cap a llevant, amb la intenció d'arribar fins al Turó del Vent. Per anar-hi, ho podem fer directament, o tornar al Turó de Sant Sebastià per anar després cap el lloc de destí.

També podem passar pel Bosc de Guanta anant després cap a la Serra Lisa. En qualsevol cas, en arribar a les immediacions del Turó del Vent, farem una nova aturada. Per arribar-hi, haurem efectuat un recorregut entre 2 i $3 \mathrm{Km}$, segons el recorregut, aproximadament.

En aquest recorregut, hem anat trobant fonamentalment els nivells rogencs del Paleocè, els quals es troben constituïts per trams de calcolutites i de gresos. Tot i així, en arribar a l'indret de la present aturada, haurem començat a trobar afloraments dels materials carbonatats del Muschelkalk Superior, del Triàsic Mig. El contacte entre uns materials i els altres es realitza per les immediacions del Turó del Vent, pels seus sectors meridionals. (fotografia 3). 


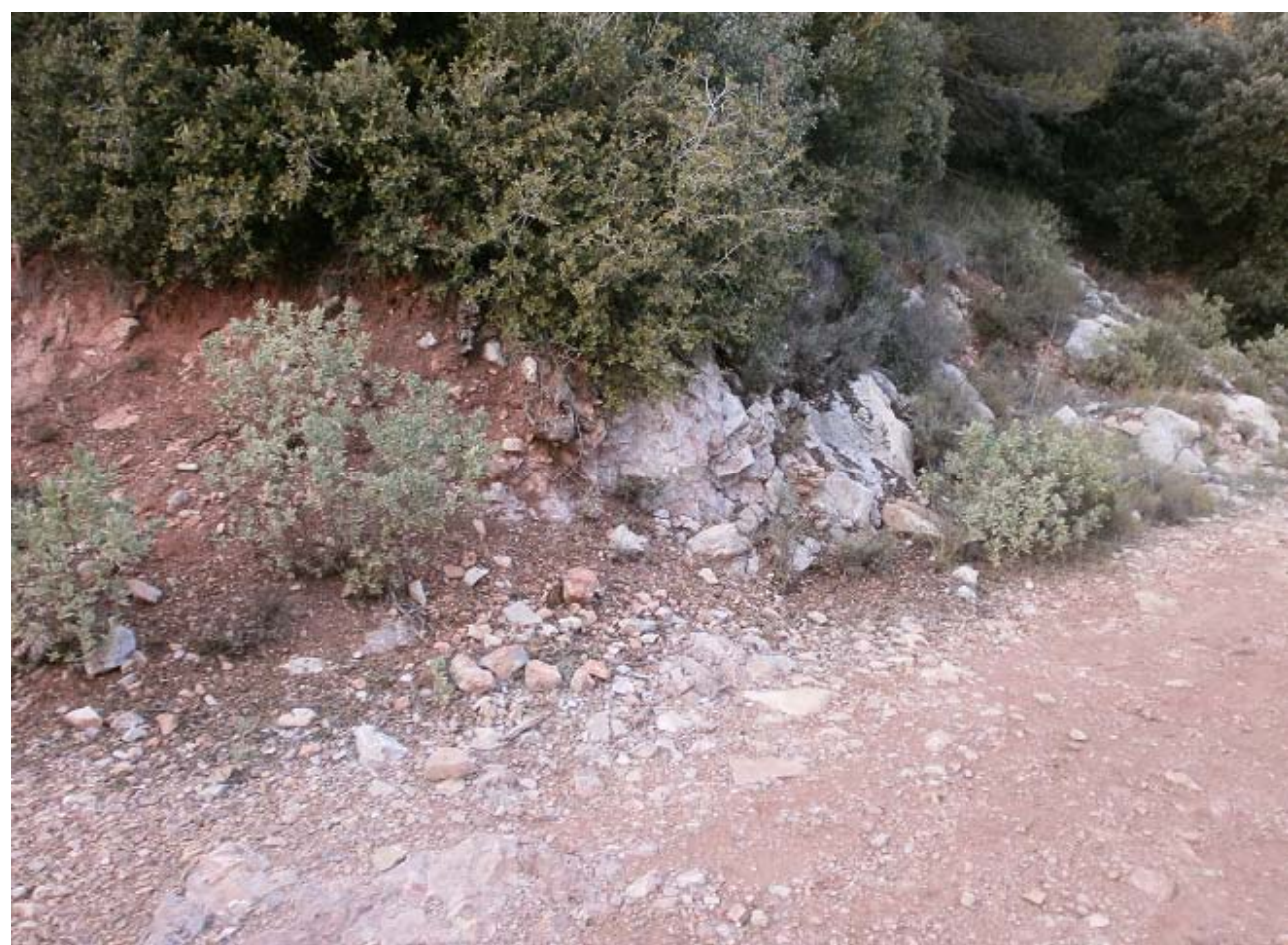

Fotografia 3. Contacte entre els nivells carbonatats del Muschelkalk Superior i les calcolutites roges del Paleocè. Al Sud del Turó del Vent

Aquest contacte es realitza mitjançant un encavalcament dels materials triàsics sobre els del Paleocè. 


\subsection{Parada 6. EL FARELL, (Sant Sebastià de Montmajor, terme municipal de Caldes de Montbui, comarca del Vallès Oriental). (Full 392).}

Després de fer l'aturada anterior, cal entrar en la Urbanització del Farell, travessar-la pels seus sectors més occidentals, amb la intenció d'arribar fins a l'antiga Masia del Farell. En arribar-hi, farem una nova aturada, a menys de 1'5 Km de la parada anterior, aproximadament.

Visió de part dels Catalànids (Sistema Mediterrani) des de les immediacions del Farell.

En primer terme, apareixen alguns indrets de la Serralada Prelitoral Catalana, una mica tapats per la vegetació. A mig terme, apareix la Depressió Prelitoral Catalana.

I al fons, es poden veure els relleus de la Serralada Litoral Catalana (que en aquests indrets correspon al Montnegre i al Corredor)

En aquest recorregut, hem anat trobant afloraments dels materials carbonatats triàsics, esmentats a l'aturada anterior. Aquests materials constitueixen els punts més alts del Turó del Vent i també del Turó del Farell, prop d’on estem ara circulant en aquest recorregut.

Per d'altra banda, en bona part del recorregut, s'ha fet força palesa la Depressió Prelitoral Catalana, per on es troben les poblacions de Caldes de Montbui i Sentmenat, entre altres. (fotografia 4).

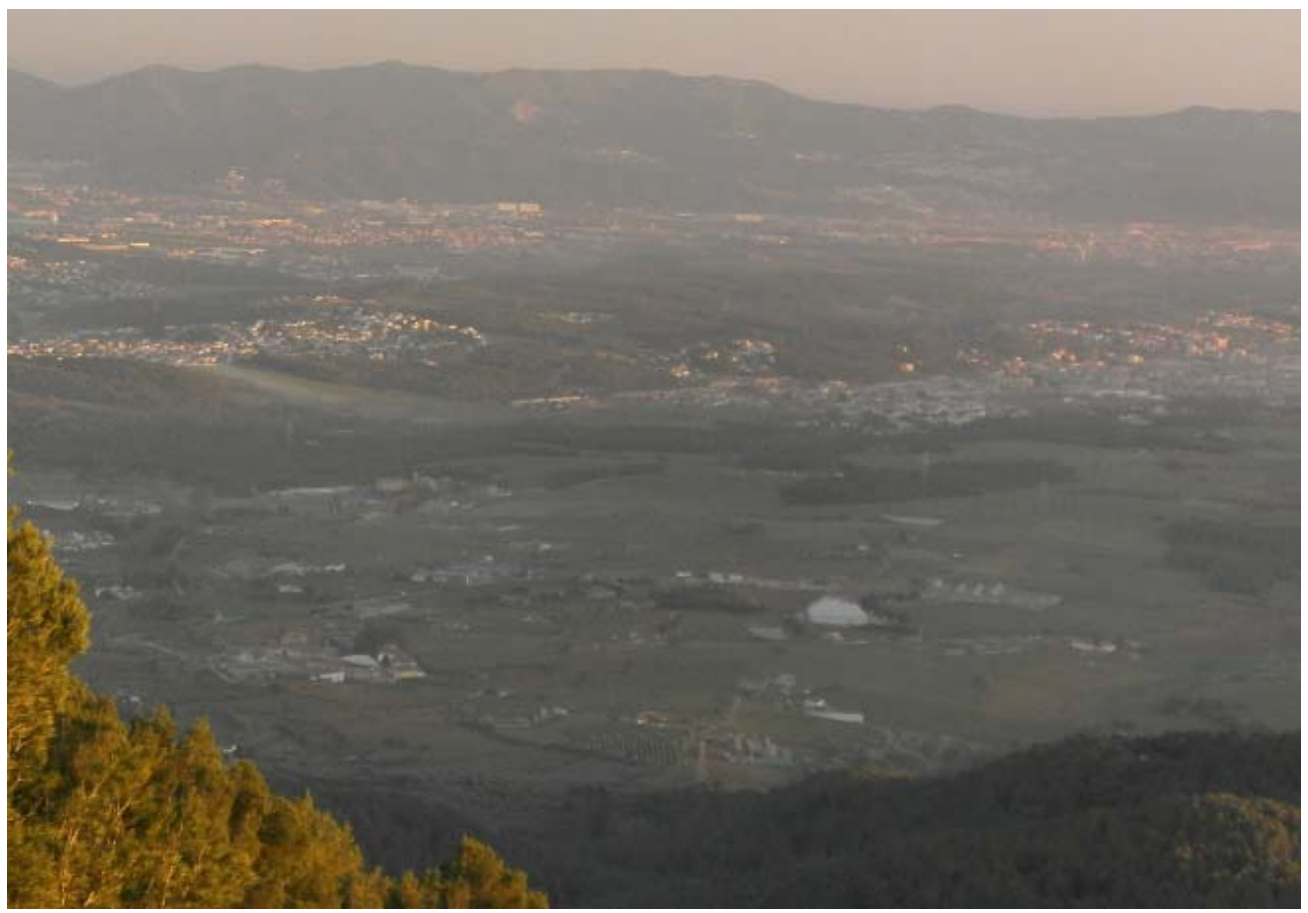

Fotografia 4. Visió de part dels Catalànids (Sistema Mediterrani) des de les immediacions del Farell.

En primer terme, apareixen alguns indrets de la Serralada Prelitoral Catalana, una mica tapats per la vegetació. A mig terme, apareix la Depressió Prelitoral Catalana.

I al fons, es poden veure els relleus de la Serralada Litoral Catalana (que en aquests indrets correspon al Montnegre i al Corredor) 
Més endavant, en arribar a la Masia del Farell, s'han fet molt evidents els afloraments dels materials carbonatats triàsics del Muschelkalk Superior. Aquests materials (eminentment calcaries i dolomies) es troben intensament replegats, com es pot veure al costat de la masia. (fotografía 5).

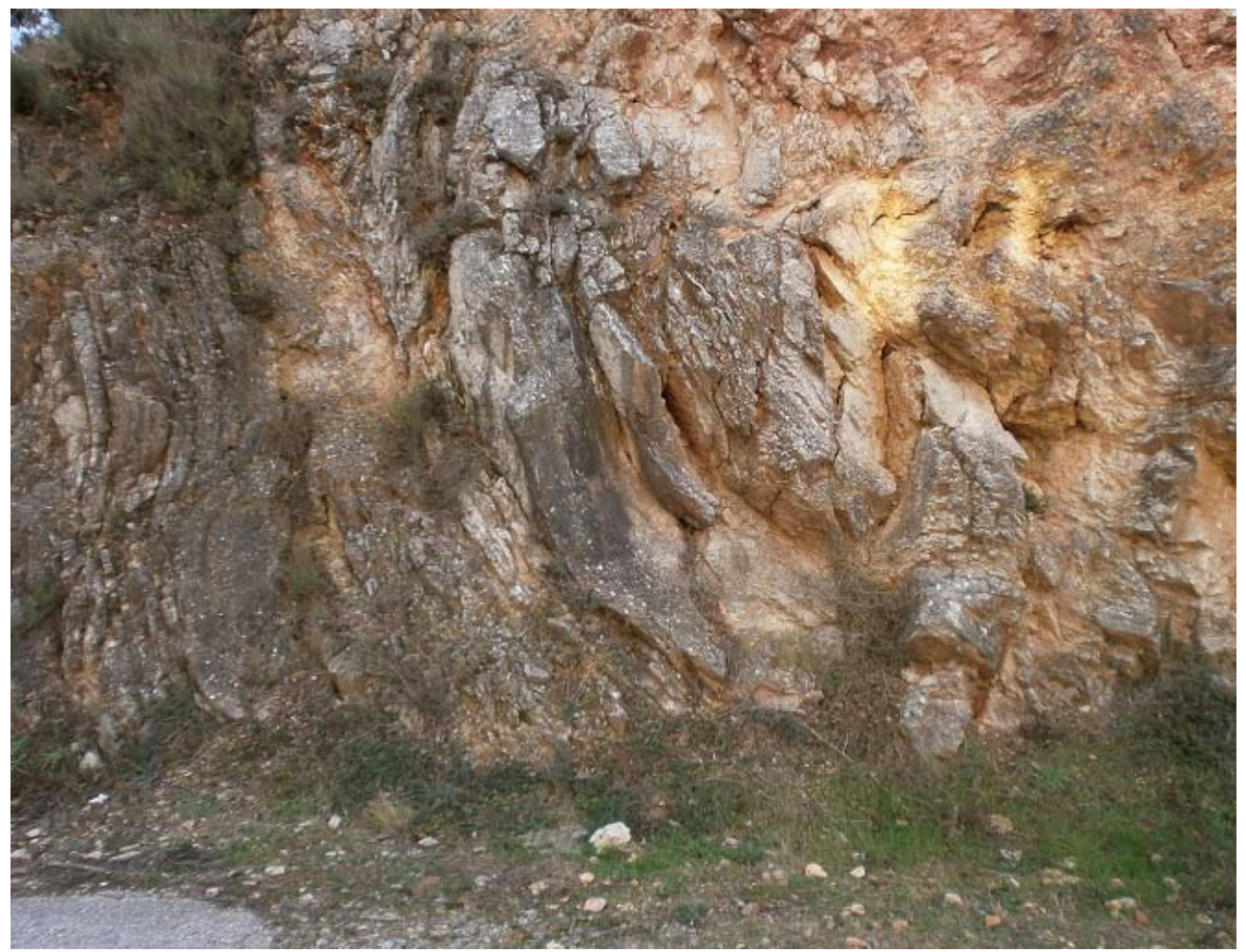

Fotografia 5. Afloraments dels materials carbonats del Muschelkalk Superior (Triàsic Mig), per les immediacions de la Masia del Farell. Aquests materials de la Serralada Prelitoral Catalana, es troben intensament replegats, en aquest indret

Parada 7 - CONDICIONAL. URBANITZACIÓ DEL FARELL, (Sant Sebastià de Montmajor, terme municipal de Caldes de Montbui, comarca del Vallès Oriental). (Full 392).

Després de fer l'aturada anterior, sols ens cal ara acabar de recórrer tota la Urbanització del Farell, amb la intenció d'arribar fins a l'entrada, a tocar de la carretera local BV - 1243, per on iniciat el recorregut d'aquest itinerari. Així, ens caldrà recórrer uns 1’ 5 Km, aproximadament.

En aquest recorregut, hem trobat pocs afloraments, com a conseqüència de les construccions de la urbanització. Tot i això, s' han fet palesos alguns afloraments dels materials carbonatats del Triàsic Superior, similars als que hem trobat a l'aturada anterior; i també en els recorreguts anteriors.

Tot i que aquests afloraments dels materials carbonatats no els haurem vist, en aquest recorreguts, si que es veuen be des del recorregut de la Urbanització del Farell cap el poble de Sant Sebastià de Montmajor. En aquest recorregut, aquests materials carbonatats es fan palesos per sota de les cases, al Nord de la Urbanització del Farell. (fotografia 6). 


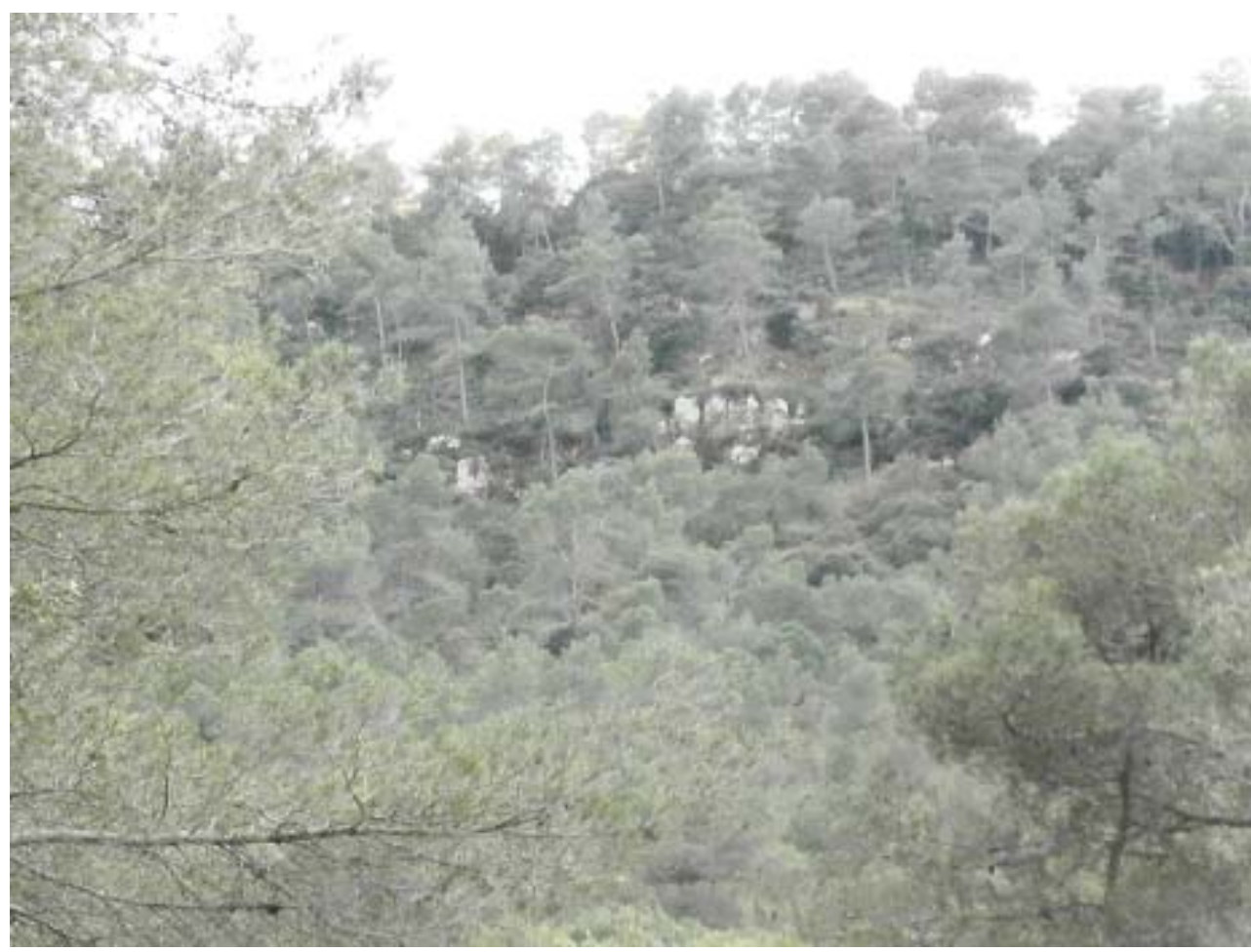

Fotografia 6. Aflorament dels materials carbonatats triàsics (del Muschelkalk Superior) per sota de les cases a la Urbanització del Farell, en el seu sector septentrional, des de la carretera a Sant Sebastià de Montmajor

En aquest indret finalitza el recorregut de l'itinerari.

\section{Bibliografia}

GUIMERÀ, J. et altri (1992).- Geologia (II), Història Natural dels Països Catalans, Vol.2, 547 pag. Enciclopèdia Catalana, S.A. Barcelona.

IGME (1976).- Mapa Geológico de España a escala 1:50.000 (segunda Série). Hoja y memória de la hoja no 392 (Sabadell). Inst. Geol. Minero de españa. Minist. Indústria. Madrid.

MATA - PERELLÓ, J.M. (1991).- Els Minerals de Catalunya. Arxius de la Secció de Ciències, t. XCIII, 442 pag. Institut d'Estudis Catalans. Barcelona.

RIBA, O. et altri (1976).- Geografia Física dels Països Catalans, Edit. Ketres, 217 pag. Barcelona. 